\title{
New Destruxins from the Marine-derived Fungus Beauveria felina
}

\author{
Simone P. Lira, Aline M. Vita-Marques, Mirna H. R. Seleghim, Tim S. Bugni, \\ Daniel V. LaBarbera, Lara D. Sette, Sandra R. P. Sponchiado, Chris M. Ireland, \\ Roberto G. S. Berlinck
}

Dedicated to the memory of Professor Kenneth L. Rinehart.

Received: June 2, 2006 / Accepted: September 13, 2006

(C) Japan Antibiotics Research Association

\begin{abstract}
Chemical investigation of the cytotoxic and anti-tuberculosis active butanone extract obtained from the growth media of the marine-derived fungus Beauveria felina led to the isolation of two new destruxins, $[\beta$-MePro] destruxin E chlorohydrin (1) and pseudodestruxin C (3), along with five known cyclic depsipeptides. The structures of the new destruxin derivatives were established by analysis of spectroscopic data, while the absolute configuration of the common amino acid residues was established by Marfey's analysis. The absolute configuration of the 2(R),4(S)-5-chloro-2,4-dihydroxypentanoic acid residue in 1 could be established by application of a $J$-based configuration method followed by derivatization with $R$-MPA-Cl and NMR analysis.
\end{abstract}

Keywords Fungi, Beauveria felina, marine microorganisms, destruxins

\section{Introduction}

During the past fifteen years, marine fungi have received increasing attention as a source of biologically active secondary metabolites $[1,2]$. We have recently initiated the first research program in Brazil to search for new biologically active secondary metabolites from marinederived bacteria and fungi $[3,4]$. Chemical and biological screening of extracts obtained from 57 marine-derived fungal strains led to chemical studies of a cytotoxic and anti-tuberculosis active extract from the culture media of a marine-derived Beauveria felina. This chemical investigation led to the isolation of two new cyclodepsipeptides, $[\beta$-MePro] destruxin E chlorohydrin (1) and pseudodestruxin $\mathrm{C}$ (3), along with the known destruxin E chlorohydrin (2), $\left[\mathrm{Phe}^{3}, \mathrm{~N}-\mathrm{Me}-\mathrm{Val}^{5}\right]$ destruxin B (4), roseotoxin B (5), roseocardin (6) and isariin B (7). Herein we report the isolation and structure determination of compounds $\mathbf{1}$ and 3 , including the absolute stereochemistry of the $2(R), 4(S)$ 5-chloro-2,4-dihydroxypentanoic acid residue in $\mathbf{1}$.

\section{Experimental}

\section{General Experimental}

The NMR data were recorded in $5: 1 \mathrm{MeCN}-d_{3} / \mathrm{DMSO}-d_{6}$ on a Varian INOVA spectrometer equipped with a Nalorac
R. G. S. Berlinck (Corresponding author), S. P. Lira, A. M. Vita-Marques, M. H. R. Seleghim: Instituto de Química de São Carlos, Universidade de São Paulo, CP 780, CEP 13560-970, São Carlos, SP, Brazil, E-mail: rgsberlinck@iqsc.usp.br

T. S. Bugni, D. V. LaBarbera, C. M. Ireland: Department of Medicinal Chemistry, University of Utah, Salt Lake City, Utah 84112, USA
L. D. Sette: Divisão de Recursos Microbianos, Centro Pluridisciplinar de Pesquisas Químicas, Biológicas e Agrícolas, Universidade Estadual de Campinas, CP 6171, 13083-970, Campinas, SP, Brazil

S. R. P. Sponchiado: Departamento de Bioquímica e Tecnologia Química, Universidade Estadual Paulista, Araraquara, SP, Brazil 
MDBG $3 \mathrm{~mm}$ probe operating at $500 \mathrm{MHz}$ for ${ }^{1} \mathrm{H}$ and $125 \mathrm{MHz}$ for ${ }^{13} \mathrm{C}$ using standard pulse sequences, or in DMSO- $d_{6}$ and $\mathrm{MeOH}-d_{4}$ on a Bruker DRX500 $11.7 \mathrm{~T}$, operating at $500.13 \mathrm{MHz}$ for ${ }^{1} \mathrm{H}$ and $125.76 \mathrm{MHz}$ for ${ }^{13} \mathrm{C}$, respectively. The gHETLOC was recorded on a $600 \mathrm{MHz}$ Varian INOVA spectrometer equipped with a $5 \mathrm{~mm}$ cryoprobe. NMR spectra were recorded using either TMS or the signal of the residual non-deuterated solvent as reference. Mass spectrometry was performed using a Micromass Q-Tof micro equipped with lockspray. Accurate mass measurements for isariin B were performed using leucine enkephalin as a lock mass. Data were processed using MassLynx 4.0. Optical rotations were measured on a Jasco DIP-370 polarimeter. IR spectra were recorded on a Jasco FTIR-420 spectrophotometer. UV spectra were obtained using a Perkin Elmer UV/VIS spectrometer Lambda2. All commercially available reagents and amino acid standards were purchased and used without additional purification. All solvents were HPLC grade.

\section{Biological Material}

The fungus was obtained from a Caulerpa sp. alga. The alga was collected with sterile tweezers at Cabelo Gordo de Fora beach, São Sebastião, São Paulo state north coastline (S 23 $49^{\prime} 656^{\prime \prime} ; \mathrm{W} 45^{\circ} 25^{\prime} 351^{\prime \prime}$ ) and stored in sterile seawater. The algal sample was vortexed for one minute, and $200 \mu \mathrm{l}$ of the aqueous sample was inoculated on MF agar, and the plates were incubated for 7 days at $25^{\circ} \mathrm{C}$. After exhaustive purification, pure isolates were preserved with silica-gel in sealed eppendorf tubes and stored at $4^{\circ} \mathrm{C}$.

Seed cultures were prepared in two culture tubes $(12 \mathrm{ml})$ containing $5 \mathrm{ml}$ of MF agar and incubated for 7 days at $25^{\circ} \mathrm{C}$. After incubation, inoculum was prepared by adding a $0.85 \% \mathrm{NaCl}$ solution to each tube and scraping the agar surface. The inoculum was transferred to $250 \mathrm{ml}$ of MF production medium in a $500 \mathrm{ml}$ erlenmeyer. The fungi were statically grown for 30 days at $25^{\circ} \mathrm{C}$.

\section{Extraction and Isolation}

Two hundred and fifty milliliters of methylethylketone (MEK) was added to each culture, and the resulting mixture (medium, mycelia, and MEK) was homogenized in a blender. After 24 hours of extraction the mixture was filtered, and the supernatant was transferred to a separatory funnel to separate the aqueous and organic layers. The organic extract was concentrated and dried in vacuo. The crude extract was fractionated using a Waters Sep-Pak silica gel column $(10 \mathrm{~g})$ and eluted with a gradient of 9:1 EtOAc- $\mathrm{MeOH}$ in $\mathrm{CH}_{2} \mathrm{Cl}_{2}$. A second column chromatography in the same conditions provided a peptide- enriched fraction. The peptide-containing fractions were purified by HPLC with a Phenomenex Prodigy Phenyl-3 column $(5 \mu, 100 \AA, 4.6 \times 250 \mathrm{~mm})$ eluting with $\mathrm{MeCN}$ $\mathrm{H}_{2} \mathrm{O} 45: 55$, flow rate $1 \mathrm{ml} /$ minute, to give $8.7 \mathrm{mg}$ of $[\beta$ Me-Pro] destruxin E chlorohydrin (1), $4.5 \mathrm{mg}$ of destruxin E chlorohydrin (2), $26.8 \mathrm{mg}$ of pseudodestruxin C (3), $47.4 \mathrm{mg}$ of $\left[\mathrm{Phe}^{3}, \mathrm{~N}-\mathrm{Me}-\mathrm{Val}^{5}\right]$ destruxin B (4), $7.9 \mathrm{mg}$ of roseotoxin $\mathrm{B}(5), 1.2 \mathrm{mg}$ of roseocardin (6) and $4.5 \mathrm{mg}$ of isariin $\mathrm{B}(7)$.

\section{Taxonomy}

Preliminary identification of all strains was made by macro- and microscopic analysis. Strains AcSS8 and AcSS13 were identified by molecular and conventional methods, including DNA isolation, ITS amplification and subsequently sequencing. DNA was isolated following a method already described [21]. ITS1/ITS2 regions were amplified with the primers ITS1 (5'-CCGTAGGTGAACCTGCGG-3') and ITS4 (5'-TCCTCCGCTTATTGATATGC- $\left.3^{\prime}\right)$. Polymerase chain reaction DNA amplifications were performed in final reaction mixtures $(25 \mu 1)$ containing $5 \sim 25 \mathrm{ng}$ genomic DNA, $0.4 \mu \mathrm{M}$ of each primer, $0.2 \mu \mathrm{M}$ dNTPs (Amersham Biosciences), $1.5 \mu \mathrm{M} \mathrm{MgCl}_{2}$ (Invitrogen), 2.0 U Taq polymerase (Invitrogen) and 1.0X reaction buffer (Invitrogen). Amplification reactions were performed in a PCR Sprint (Hybaid) with the following cycling conditions: initial denaturation for 5 minutes at $94^{\circ} \mathrm{C}$ followed by 30 cycles of 30 seconds at $94^{\circ} \mathrm{C}$, 30 seconds at $55^{\circ} \mathrm{C}$ and 1 minute at $72^{\circ} \mathrm{C}$ with a final extension for 10 minutes at $72^{\circ} \mathrm{C}$ and cooling to $4^{\circ} \mathrm{C}$. Amplified products were purified, quantified and subjected to sequencing using the DYEnamic ET Dye Terminator Cycle Sequencing Kit for an automated MegaBace sequencer (Amersham Biosciences). ITS1 and ITS4 primers were used for sequencing.

Sequences were compared with ITS1/ITS2 sequence data from strains available at the public database Genbank (http://www.ncbi.nem.nih.gov) by using the BLAST N sequence match routines. The sequences were aligned using the CLUSTAL X program [22] and phylogenetic and molecular evolutionary analyses were conducted using MEGA version 3.0 [23]. The Kimura two-parameter model [24] was used to estimate evolutionary distance. The phylogenetic reconstruction was done using the neighborjoining (NJ) algorithm, with bootstrap values calculated from 1,000 replicate runs, using the software routines included in the MEGA software.

After identificaton, B. felina strains AcSS8 and AcSS13 were deposited at the Brazilian Collection of Microorganisms from Environment and Industry (CBMAI, Campinas, SP, Brazil) under the numbers CBMAI 738 and 
CBMAI 739, respectively.

General Procedure for Hydrolysis and FDAA Derivitization

To a thick walled micro reaction vial containing $50 \mu \mathrm{g}$ $(0.078 \mu$ moles $)$ of each peptide was added $150 \mu \mathrm{l}$ of $6 \mathrm{~N}$ $\mathrm{HCl}$. The vial was sealed and heated at $105^{\circ} \mathrm{C}$ for 24 hours. The reaction vessel was allowed to cool to $\mathrm{rt}$ and the solvent was removed in vacuo. The resulting residue was taken up into $126 \mu \mathrm{l}$ of $0.1 \mathrm{M}$ aqueous sodium bicarbonate followed by the addition of $126 \mu \mathrm{g}$ (6 equivalents, $0.47 \mu$ moles) of 1-fluoro-2,4-dinitrophenyl-5-1-alanine amide (FDAA) in $126 \mu \mathrm{l}$ of acetone. The reaction was heated at $50^{\circ} \mathrm{C}$ under argon for 1 hour.

FDAA-derivatized Amino Acid HPLC Analysis

The reaction mixtures from the hydrolysis and FDAA derivitizations of each peptide, $\mathbf{1}$ and $\mathbf{3}$, were used without workup for HPLC analysis. A portion of the reaction mixture $15 \mu \mathrm{l}$ was analyzed using a reversed phase $\mathrm{C}_{18}(4.6 \times 250 \mathrm{~mm})$ column. The sample was eluted with a gradient of $10 \% \mathrm{MeCN}$ in $0.1 \mathrm{M}$ ammonium acetate $(\mathrm{pH}=5)$ to $20 \% \mathrm{MeCN}$ over 60 minutes. The gradient was then increased to $50 \% \mathrm{MeCN}$ over 90 minutes. The absolute stereochemistry were determined by comparing retention times of $\mathrm{L}$ and DL amino acid standards derivatized with L-FDAA with the natural product derivatized amino acids. HPLC retention times in minutes for the amino acid standards: L- $N$-methylalanine (47.27), D- $N$-methylalanine (56.17), L-isoleucine (73.45), D-isoleucine (92.93), L- $N$ methylvaline (79.0), D- $N$-methylvaline (90.65), Lphenylalanine (81.00), D-phenylalanine (95.77).

[ $\beta$-Me-Pro] Destruxin E Chlorohydrin (1)

HPLC retention times in minutes: $L-N$-methylalanine

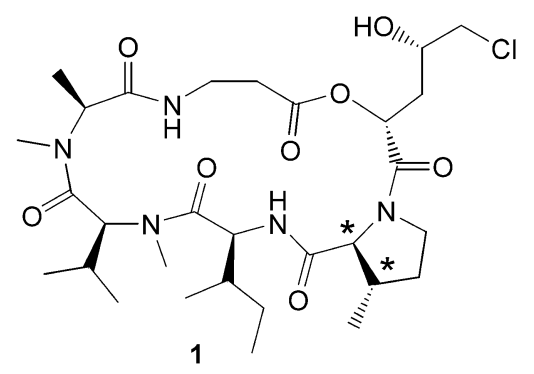<smiles></smiles><smiles>CC(C)C[C@H]1OC(=O)CCNC(=O)[C@H](C(C)C)N(C)C(=O)[C@H](C(C)C)N(C)C(=O)[C@H](Cc2ccccc2)NC(=O)[C@@H]2[C@@H](C)CCN21</smiles><smiles>CC(C)CC1OC(=O)CCNC(=O)C(C(C)C)N(C)C(=O)C(C(C)C)N(C)C(=O)C(Cc2ccccc2)NC(=O)C2CCCN2C1=O</smiles><smiles>C=CC[C@H]1OC(=O)CCNC(=O)[C@H](C)N(C)C(=O)[C@@H](C(C)C)N(C)C(=O)[C@H](C(C)CC)[C@H]1C(=O)N1CC[C@@H](C)[C@H]1C</smiles><smiles>CCC(C)C(NC(=O)C1C(C)CCN1C(=O)C(CC(C)C)OC(=O)CCNC(=O)C(C)N(C)C(=O)C(C)C)C(C)C</smiles>

Fig. 1 Structures of the new destruxins $\mathbf{1}$ and $\mathbf{3}$ and of known destruxins $\mathbf{2}, \mathbf{4} \sim \mathbf{6}$, isolated from $B$. felina.

* Indicates relative stereochemistry. 
(46.10), L-isoleucine (74.62), L- $N$-methylvaline (80.66).

Psuedodestruxin C (3)

HPLC retention times in minutes: L- $N$-methylvaline (79.07), L-phenylalanine (81.93).

\section{Physico-chemical Properties}

[ $\beta$-Me-Pro] Destruxin E Chlorohydrin (1)

$\mathrm{C}_{30} \mathrm{H}_{51} \mathrm{ClN}_{5} \mathrm{O}_{8}$ MW 644.19 (see Figure 1); $[\alpha]_{\mathrm{D}}^{25}=-0.2$ $\left(c=0.09, \mathrm{CHCl}_{3}\right)$; UV $\left(\mathrm{CH}_{2} \mathrm{Cl}_{2}\right) \lambda_{\max } \mathrm{nm}(\varepsilon) 242(6,508)$; IR $v_{\max }(\mathrm{NaCl}$ plate $) \mathrm{cm}^{-1} 3286,2965,1726,1677,1658$, $1641,1629,1548,1443,1181,755$; ESIMS $[\mathrm{M}+\mathrm{H}]^{+}=m / z$ 644.3426, calcd. for $\mathrm{C}_{30} \mathrm{H}_{50} \mathrm{ClN}_{5} \mathrm{O}_{8}(\Delta=1.1 \mathrm{ppm})$.

\section{Psuedodestruxin $\mathrm{C}(\mathbf{3})$}

$\mathrm{C}_{36} \mathrm{H}_{55} \mathrm{~N}_{5} \mathrm{O}_{7} \mathrm{MW} 669.85$ (see Figure 1); $[\alpha]_{\mathrm{D}}^{25}=-122.4$ $(c=0.02, \mathrm{MeOH}) ; \mathrm{UV}\left(\mathrm{CH}_{2} \mathrm{Cl}_{2}\right) \lambda_{\text {max }} \mathrm{nm}(\varepsilon) 230(6,511)$; IR $v_{\max }(\mathrm{NaCl}$ plate $) \mathrm{cm}^{-1} 2991,1724,1690$, $1665,1641,1611,1549,1529,1462,1442$; FABMS $[\mathrm{M}+\mathrm{H}]^{+}=m / z$ 670.4149, calcd. for $\mathrm{C}_{36} \mathrm{H}_{56} \mathrm{~N}_{5} \mathrm{O}_{7} 670.4179$ $(\Delta=-4.5 \mathrm{ppm})$.

Preparation of $R$-Methoxyphenylacetyl Chloride [25, 26] DMF (1.2 $\mu$ moles) was added to $R$-methoxyphenylacetic acid $(0.012 \mathrm{mmoles})$ followed by the addtion of $3.0 \mathrm{ml}$ of anhydrous hexanes. Subsequently, oxalyl chloride $(0.12$ mmoles) was added, and the solution was stirred for 2 days. The solvent was removed in vacuo and the product was immediately used in the preparation of the $R$-MPA ester of $\mathbf{1}$.

$R$-MPA Ester of [ $\beta$-Me-Pro] Destruxin E Chlorohydrin (1) A solution of freshly prepared $R$-MPA-Cl $(369.2 \mu \mathrm{g}$, 0.002 mmoles) in $100 \mu \mathrm{l}$ of anhydrous $\mathrm{CH}_{2} \mathrm{Cl}_{2}$ was added to a solution of $\mathbf{1}(0.5 \mathrm{mg}, 0.00078 \mathrm{mmoles})$ in $200 \mu \mathrm{l}$ of anhydrous $\mathrm{CH}_{2} \mathrm{Cl}_{2}$ followed by the addition of $2 \mu \mathrm{l}$ of pyridine. The addition of only a small amount of pyridine without DMAP or $\mathrm{Et}_{3} \mathrm{~N}$ led to a low yield $(\sim 0.17 \sim 0.20 \mathrm{mg})$ of the $R$-MPA ester, but the formation of an epoxide from the chlorhydrin was not observed. The solution was left at $\mathrm{rt}$ for 16 hours, and the solvent was removed under a stream of argon. The MPA ester of 1 was purified by HPLC using a Luna phenylhexyl column $(10 \times 250 \mathrm{~mm})$. A linear 30 minute gradient ( $4.0 \mathrm{ml} /$ minute) from $40 \% \mathrm{MeCN} / \mathrm{H}_{2} \mathrm{O}$ to $100 \% \mathrm{MeCN}$ was employed. [ $\beta$-Me-Pro] Destruxin E chlorohydrin (1) $(\sim 0.33 \mathrm{mg})$ starting material eluted at 8.6 minutes and the $R$-MPA-1 ester eluted at 15.7 minutes. The amount of recovered starting material and product was estimated from the HPLC integration of each peak at $210 \mathrm{~nm}$. ESIMS $\mathrm{m} / \mathrm{z}$ $[\mathrm{M}+\mathrm{H}]^{+} 792.3$.

\section{Results and Discussion}

The crude extract obtained from the culture medium of a marine-derived B. felina strain displayed anti-tuberculosis activity against Mycobacterium tuberculosis H37Rv (MIC at $65 \mu \mathrm{g} / \mathrm{ml}$ ) and cytotoxic activity against MCF-7 (breast), HCT-8 (colon) and B16 (murine melanoma) cancer cell lines, at $125 \mu \mathrm{g} / \mathrm{ml}$. Isolation was initially bioassay guided, and monitored by ${ }^{1} \mathrm{H}$ NMR during the HPLC separations, but the purified peptides were essentially inactive. The cyclodepsipeptide [ $\beta$-Me-Pro] destruxin E chlorohydrin (1) was isolated as a white amorphous solid. On the basis of accurate mass measurements and NMR data, its molecular formula was assigned as $\mathrm{C}_{30} \mathrm{H}_{50} \mathrm{ClN}_{5} \mathrm{O}_{8}$. The intense $[\mathrm{M}+2+\mathrm{H}]^{+}$peak observed in the ESI mass spectrum of $\mathbf{1}$ further supported the presence of one chlorine atom. The ${ }^{1} \mathrm{H}$ NMR data was very suggestive of a cyclic peptide, with $\alpha$ protons between $\delta 4.00$ and $\delta 5.00$, two amide protons $\left(\delta_{\mathrm{N}-\mathrm{H}} 8.05\right.$ and $\left.\delta_{\mathrm{N}-\mathrm{H}} 6.90\right)$ and two $N$-methyl groups $\left(\delta_{\mathrm{H}}\right.$ 3.20 and $\left.\delta_{\mathrm{H}} 2.63\right)$. A search in the Chemical Abstracts database, revealed two compounds with similar structural features destruxin-A4 chlorohydrin [5] and destruxin E chlorohydrin (2) [6].

A detailed inspection of the NMR data and a 14 AMU difference between $\mathbf{1}$ and $\mathbf{2}$ suggested that $\mathbf{1}$ was [ $\beta$-MePro] destruxin E chlorohydrin. The amino acid sequence was established by ROESY and HMBC correlations as identical to that of destruxin E chlorohydrin (2), with the exception of the presence of the $\beta$-Me-Pro methyl group signal at $\delta 1.09(\mathrm{~d}, 7.0 \mathrm{~Hz})$ and a $\beta$-methine multiplet at $\delta$ 2.54 . The sequence of the residues in [ $\beta$-Me-Pro] destruxin E chlorohydrin (1) was established as follows. A ROESY correlation was observed between the proton at the $\alpha$ position of the pentanoic acid residue $(\delta 5.14, \mathrm{t}, 7.0 \mathrm{~Hz})$ and both protons at the $\delta$-position of the $\beta$-Me-Pro amino acid (at $\delta 3.83$, ddd, 3.9, 9.1, $9.1 \mathrm{~Hz}$ and $\delta 3.93, \mathrm{~m}$ ). Analysis of ${ }^{1} \mathrm{H}-{ }^{1} \mathrm{H}$ COSY and $\mathrm{HMBC}$ spectra enabled us to construct the complete $\beta$-Me-Pro spin system, from the $\delta$ position protons to the $\alpha$-position proton at $\delta 4.04$ (d, $2.0 \mathrm{~Hz}$ ). HMBC correlations from both the $\beta$-Me-Pro $\alpha$ proton and the Ile amide proton $(\delta 6.90, \mathrm{~d}, 9.0 \mathrm{~Hz})$ to the carbonyl at $\delta 169.1$ confirmed that an Ile residue followed the $\beta$-Me-Pro. From the Ile $\alpha$-proton $(\delta 4.83$, dd, 6.5 and $9.5 \mathrm{~Hz}$ ), a ROESY correlation to the subsequent $N$-Me group ( $\delta 3.20)$ of the $N$-Me-Val residue confirmed the sequence as ( $\beta$-Me-Pro)-(Ile)-( $N$-Me-Val). Further NOE correlations observed in the ROESY spectrum from the $N$ Me-Val $\alpha$-proton $(\delta 4.99, \mathrm{~d}, 11.0 \mathrm{~Hz})$ to the methyl group of $N$-Me-Ala residue (at $\delta 2.63$ ), as well as a strong correlation from the $N$-Me-Ala $\alpha$-proton $(\delta 5.18$, t, $7.0 \mathrm{~Hz})$ 
Table $1{ }^{1} \mathrm{H}$ NMR data for [ $\beta$-Me-Pro] destruxin E chlorohydrin (1) and pseudodestruxin C (3)

\begin{tabular}{|c|c|c|}
\hline \multirow{2}{*}{ Position } & 1 & 3 \\
\hline & ${ }^{1} \mathrm{H} \delta$ mult. $(\mathrm{J} \text { in } \mathrm{Hz})^{\mathrm{a}}$ & ${ }^{1} \mathrm{H} \delta$ mult. $(J \text { in } \mathrm{Hz})^{\mathrm{b}}$ \\
\hline & 5-Chloro-2,4-dihydroxy pentanoic acid & 2-Hydroxy-4-methylpentanoic acid \\
\hline$\alpha$ & $5.14 \mathrm{t}(7.0)$ & $5.29 \mathrm{dd}(1.5,11.5)$ \\
\hline \multirow[t]{2}{*}{$\beta, \beta^{\prime}$} & $2.07 \mathrm{ddd}(7.0,8.3,13.8)$ & $1.35 \mathrm{ddd}(1.5,10.0,14.5)$ \\
\hline & 2.13 ddd $(4.8,7.0,13.8)$ & 1.87 ddd $(3.5,11.5,15.0)$ \\
\hline$\gamma$ & 3.76 ddd $(4.5,4.8,5.6,8.3)$ & $1.96 \mathrm{~m}$ \\
\hline$\delta$ & $3.61 \mathrm{dd}(5.6,11.2)$ & $1.01 \mathrm{~d}(5.4)$ \\
\hline \multirow[t]{2}{*}{$\delta^{\prime}$} & $3.65 \mathrm{dd}(4.5,11.2)$ & $1.03 d(5.0)$ \\
\hline & $\beta$-Alanine & $\beta$-Alanine \\
\hline$\alpha, \alpha^{\prime}$ & $3.01 \mathrm{~m}, 3.92 \mathrm{~m}$ & $3.31 \mathrm{~m}, 4.06 \mathrm{dt}(3.4,13.7)$ \\
\hline$\beta, \beta^{\prime}$ & $2.46 \mathrm{ddd}(2.0,11.5,18.0), 2.69 \mathrm{dd}(4.5,18.0)$ & $2.50 \mathrm{~m}, 2.74 \mathrm{dt}(3.0,15.0)$ \\
\hline \multirow[t]{2}{*}{$\mathrm{N}-\mathrm{H}$} & $8.05(b r d, 9.0)$ & \\
\hline & N-Me-alanine & N-Me-valine (1) \\
\hline$\alpha$ & $5.18 \mathrm{t}(7.0)$ & $4.42 \mathrm{~d}(10.5)$ \\
\hline$\beta$ & $1.23 \mathrm{~d}(7.0)$ & $2.40 \mathrm{~m}$ \\
\hline$\gamma$ & & $0.95 \mathrm{~d}(6.5)$ \\
\hline$\delta$ & & $0.91 \mathrm{~d}(6.5)^{c}$ \\
\hline \multirow[t]{2}{*}{$\mathrm{N}-\mathrm{Me}$} & $2.63 \mathrm{~s}$ & $2.95 \mathrm{~s}$ \\
\hline & N-Me-valine & N-Me-valine (2) \\
\hline$\alpha$ & $4.99 \mathrm{~d}(11.0)$ & $5.17 \mathrm{~d}(10.6)$ \\
\hline$\beta$ & 2.27 dqq $(11.0,7.0,7.0)$ & $2.41 \mathrm{~m}$ \\
\hline$\gamma$ & $0.90 \mathrm{~d}(7.0)$ & $0.89 \mathrm{~d}(6.5)^{c}$ \\
\hline$\delta$ & $0.93 d(7.0)$ & $0.90 \mathrm{~d}(6.5)^{c}$ \\
\hline \multirow[t]{2}{*}{$\mathrm{N}-\mathrm{Me}$} & $3.20 \mathrm{~s}$ & $3.08 \mathrm{~s}$ \\
\hline & Isoleucine & Phenylalanine \\
\hline$\alpha$ & 4.83 dd $(6.5,9.5)$ & $4.71 \mathrm{dd}(5.2,10.8)$ \\
\hline$\beta$ & $1.90 \mathrm{~m}$ & $2.97 \mathrm{dd}(10.8,13.8)$ \\
\hline$\beta^{\prime}$ & & $3.16 \mathrm{dd}(5.2,13.8)$ \\
\hline$\gamma, \gamma^{\prime}$ & $1.31 \mathrm{~m}, 1.49 \mathrm{~m}$ & \\
\hline$\delta, \delta^{\prime}$ & $0.83 \mathrm{~d}(7.0)$ & $7.30 \mathrm{~m}$ \\
\hline$\varepsilon, \varepsilon^{\prime}$ & $0.84 \mathrm{~d}(7.0)$ & $7.27 \mathrm{~m}$ \\
\hline$\phi$ & & $7.24 \mathrm{~m}$ \\
\hline \multirow[t]{2}{*}{$\mathrm{N}-\mathrm{H}$} & $6.90 \mathrm{~d}(9.0)$ & \\
\hline & $\beta$-Methylproline & $\beta$-Methylproline \\
\hline$\alpha$ & $4.04 \mathrm{~d}(2.0)$ & $3.72 \mathrm{~d}(2.5)$ \\
\hline$\beta$ & $2.54 \mathrm{~m}$ & $2.40 \mathrm{~m}$ \\
\hline$\gamma, \gamma^{\prime}$ & 1.70 ddd $(3.9,7.2,12.8), 2.0 \mathrm{~m}$ & $1.49 \mathrm{~m}$ \\
\hline$\delta, \delta^{\prime}$ & 3.83 ddd $(3.9,9.1,9.1), 3.93 \mathrm{~m}$ & 3.33 m, 3.68 dt $(8.8,11.9)$ \\
\hline$\beta$-Me & $1.09 \mathrm{~d}(7.0)$ & $1.09 \mathrm{~d}(7.0)$ \\
\hline
\end{tabular}

${ }^{\text {a }}$ Recorded in $3: 1 \mathrm{MeCN}-d_{3} / \mathrm{DMSO}-d_{6} ;{ }^{b}$ recorded in $\mathrm{MeOH}-d_{4} ;{ }^{c}$ assignments are interchangeable.

to the amide proton of the $\beta$-Ala (at $\delta 8.05$, brd, $9.0 \mathrm{~Hz}$ ) confirmed the amino acid and $\alpha$-hydroxy acid sequence as shown in Figure 1 for [ $\beta$-Me-Pro] destruxin E chlorohydrin (1) (Tables 1 and 2). Additionally, the ROESY data suggested that the relative stereochemistry between the $\alpha$ and the $\beta$-proton of $\beta$-Me-Pro was trans, since a strong
NOE correlation between the $\beta$-methyl and the $\alpha$-proton was observed. The stereochemistry of the Ile, $N$-Me-Val, and $N$-Me-Ala residues was established as $S$ by Marfey's analysis [7]. No commercial standards were available to assign the absolute stereochemistry of the $\beta$-Me-Pro residue. 
Table $2{ }^{13} \mathrm{C}$ NMR data for [ $\beta$-Me-Pro] destruxin E chlorohydrin (1) and pseudodestruxin C (3)

\begin{tabular}{|c|c|c|}
\hline \multirow{2}{*}{ Position } & 1 & 3 \\
\hline & ${ }^{13} \mathrm{C}(\delta)$ & ${ }^{13} \mathrm{C}(\delta)$ \\
\hline & 5-Chloro-2,4-dihydroxy pentanoic acid & 2-Hydroxy-4-methylpentanoic acid \\
\hline$\alpha$ & 70.6 & 74.6 \\
\hline$\beta$ & 35.2 & 40.1 \\
\hline$\gamma$ & 66.9 & 26.1 \\
\hline$\delta, \delta^{\prime}$ & 49.2 & $21.4,23.8$ \\
\hline \multirow[t]{2}{*}{$\mathrm{C}=\mathrm{O}$} & 170.6 & 172.5 \\
\hline & $\beta$-Alanine & $\beta$-Alanine \\
\hline$\alpha$ & 32.8 & $35.9^{a}$ \\
\hline$\beta$ & 34.2 & 36.9 \\
\hline \multirow[t]{2}{*}{$\mathrm{C}=\mathrm{O}$} & 173.5 & 175.6 \\
\hline & N-Me-alanine & N-Me-valine (1) \\
\hline$\alpha$ & 55.1 & 67.9 \\
\hline$\beta$ & 14.7 & $29.3^{b}$ \\
\hline$\gamma, \gamma^{\prime}$ & & $19.5,20.4^{c}$ \\
\hline $\mathrm{N}-\mathrm{Me}$ & 27.4 & 30.0 \\
\hline \multirow[t]{2}{*}{$\mathrm{C}=\mathrm{O}$} & 169.1 & 170.5 \\
\hline & N-Me-valine & N-Me-valine (2) \\
\hline$\alpha$ & 57.5 & 59.1 \\
\hline$\beta$ & 26.9 & $29.0^{b}$ \\
\hline$\gamma, \gamma^{\prime}$ & $18.8,18.7$ & $20.8^{c}, 20.0^{c}$ \\
\hline $\mathrm{N}-\mathrm{Me}$ & 30.4 & 30.4 \\
\hline \multirow[t]{2}{*}{$\mathrm{C}=\mathrm{O}$} & 170.6 & 171.8 \\
\hline & Isoleucine & Phenylalanine \\
\hline$\alpha$ & 52.9 & 55.5 \\
\hline$\beta$ & 36.9 & $36.0^{\mathrm{a}}$ \\
\hline$\gamma$ & 24.0 & 138.1 \\
\hline$\delta, \delta^{\prime}$ & 10.7 & $129.9^{d}$ \\
\hline$\varepsilon, \varepsilon^{\prime}$ & 14.7 & $130.2^{d}$ \\
\hline$\phi$ & & 128.4 \\
\hline \multirow[t]{2}{*}{$\mathrm{C}=\mathrm{O}$} & 173.5 & 171.8 \\
\hline & $\beta$-Methylproline & $\beta$-Methylproline \\
\hline$\alpha$ & 66.9 & 69.3 \\
\hline$\beta$ & 36.9 & 41.4 \\
\hline$\gamma$ & 30.4 & 29.8 \\
\hline$\delta, \delta^{\prime}$ & 44.9 & 46.9 \\
\hline$\beta$-Me & 18.4 & 19.3 \\
\hline $\mathrm{C}=\mathrm{O}$ & 169.1 & 173.3 \\
\hline
\end{tabular}

${ }^{a}$ Recorded in $3: 1 \mathrm{MeCN}-d_{3} / \mathrm{DMSO}-d_{6} ;{ }^{b}$ recorded in $\mathrm{MeOH}-d_{4} ;{ }^{c, d}$ assignments are interchangeable.

Our approach to solve the absolute stereochemistry of the 5-chloro-2,4-dihydroxypentanoic acid residue in $\mathbf{1}$ employed a combination of the $J$-based configuration method $[8,9]$ and variable temperature NMR analysis of the corresponding $R$-MPA ester derivative [10]. The goal of the $J$-based analysis was to relate the stereochemistry of the C-4 hydroxyl group to that of the $\alpha$-methine group in the 5chloro-2,4-dihydroxypentanoic acid residue. After the heteronuclear coupling constants were measured for the 5-chloro-2,4-dihydroxypentanoic acid side chain using a sensitivity-enhanced gHETLOC [11], each of the C-3 methylene protons $\left(\mathrm{H}_{1}\right.$ and $\mathrm{H}_{\mathrm{h}}$ in Figure 2) was diastereotopically labeled relative to the $\mathrm{C} \alpha$-methine hydrogen. All hydrogens in the 5-chloro-2,4 dihydroxypentanoic acid rotamers of Figures 2 and 3 have been labeled in agreement with those published 


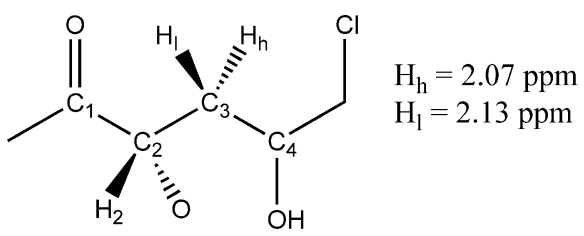

${ }^{3} J_{\mathrm{H} 2-\mathrm{H} 3 \mathrm{~h}} 7.0$ medium

${ }^{3} J_{\mathrm{H} 2-\mathrm{H} 31} 7.0$ medium

${ }^{3} J_{\mathrm{H} 2-\mathrm{C} 4}+2.2$ small

${ }^{2} J_{\mathrm{H} 3 \mathrm{~h}-\mathrm{C} 2}-5.8$ large

${ }^{2} J_{\mathrm{H} 3 \mathrm{I}-\mathrm{C} 2}-4.3$ medium

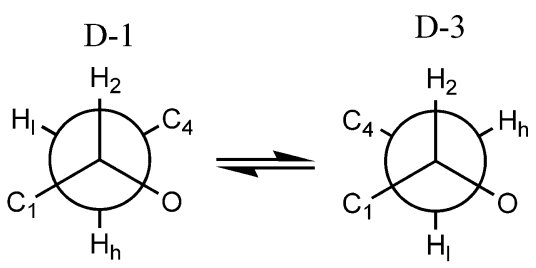

Average of coupling values for the two rotomers

${ }^{3} J_{\mathrm{H} 2-\mathrm{H} 3 \mathrm{~h}}$ medium

${ }^{3} J_{\mathrm{H} 2-\mathrm{H} 31}$ medium

${ }^{3} J_{\mathrm{H} 2-\mathrm{C} 4}$ small

${ }^{2} J_{\mathrm{H} 3 \mathrm{~h}-\mathrm{C} 2}$ large

${ }^{2} J_{\mathrm{H} 31-\mathrm{C} 2}$ medium

Fig. 2 J-based analysis and diastereotopic labeling of C-3 methylene protons.

by Matsumori et al. [8]. The starting point for the configurational analysis was the observation of a triplet $(7.0 \mathrm{~Hz}){ }^{1} \mathrm{H}$ resonance for the $\alpha$-proton of the chlorohydroxy acid residue. Equivalent $\mathrm{H}_{\alpha}-\mathrm{H}_{1}$ and $\mathrm{H}_{\alpha}-\mathrm{H}_{\mathrm{h}}$ coupling constants suggested the presence of two major conformers (see Figure 2). Although the ${ }^{3} J_{\mathrm{C} 1-\mathrm{H} 3}$ coupling constant could not be measured from the g-BIRD-HSQMBC $[8,12]$ due to low signal intensity, a unique solution was found from the available data. There were two possible conformer populations that would match the ${ }^{2} J_{\mathrm{CH}}$ values, but only one (see Figure 2) would give equivalent homonuclear coupling constants.

Once the two $\mathrm{H}-3$ protons were diastereotopically assigned, the stereochemistry at the $\alpha$-position could be related to that of the hydroxyl group at C-4. The stereochemistry of this fragment is outlined in Figure 3. The representation of the 5-chloro-2,4-dihydroxypentanoic acid relative stereochemistry and its major conformer in the Newman projection are consistent with Matsumori's model [8]. The observed coupling constants were consistent with the presence of mainly one rotamer since the homonuclear coupling constants were quite different. However, the magnitude of these couplings was consistent with a small population of a second rotamer similar to that described in Figure 2. Overall, the coupling constants were consistent with the rotamer shown in Figure 3.

The absolute stereochemistry at C-4 was established using the ${ }^{1} \mathrm{H}$ NMR method described by Riguera and coworkers [10]. A single $R$-MPA derivative was prepared in $\mathrm{CH}_{2} \mathrm{Cl}_{2}$ with a small amount of pyridine. Although our reaction conditions were not optimal for esterification, base catalyzed epoxidation of the halohydrin was not observed. Approximately $200 \mu \mathrm{g}$ of the $R$-MPA ester was isolated and analyzed by variable temperature ${ }^{1} \mathrm{H}$ NMR. The difference in chemical shifts was measured at $-1{ }^{\circ} \mathrm{C}$ and $25^{\circ} \mathrm{C}$

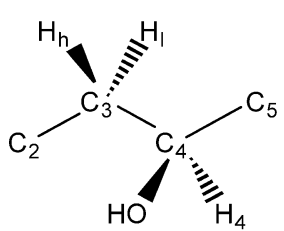

${ }^{3} J_{\mathrm{H} 4-\mathrm{H} 3 \mathrm{~h}} 8.3$ large

${ }^{3} J_{\mathrm{H} 4-\mathrm{H} 31} 4.8$ small

${ }^{3} J_{\mathrm{H} 4-\mathrm{C} 2}+2.4$ small

${ }^{2} J_{\mathrm{H} 3 \mathrm{~h}-\mathrm{C} 4}-6.3$ large

${ }^{2} J_{\mathrm{H} 3 \mathrm{l}-\mathrm{C} 4}-3.1$ small<smiles>CC1CCCCCCC1O</smiles>

${ }^{3} J_{\mathrm{H} 4-\mathrm{H} 3 \mathrm{~h}}$ large

${ }^{3} J_{\mathrm{H} 4-\mathrm{H} 31}$ small

${ }^{3} J_{\mathrm{H} 4-\mathrm{C} 2}$ small

${ }^{2} J_{\mathrm{H} 3 \mathrm{~h}-\mathrm{C} 4}$ large

${ }^{2} J_{\mathrm{H} 31-\mathrm{C} 4}$ small

Fig. 3 J-based analysis of the hydroxy relative to the methylene protons.

using ${ }^{1} \mathrm{H}$ spectra and gCOSY spectra. The experiments were cycled to ensure that conformational equilibria were reversible. Since the coupling constants did not significantly change between temperatures, each peak of the multiplet signal was recorded instead of trying to estimate the true chemical shift of each proton. The difference in the chemical shifts $\left[\Delta \delta^{\mathrm{T} 1, \mathrm{~T} 2}=\mathrm{T} 1\left(25^{\circ} \mathrm{C}\right)\right.$ minus $\left.\mathrm{T} 2\left(-1^{\circ} \mathrm{C}\right)\right]$ was large for $\mathrm{H}-2(+31.6 \mathrm{~Hz}), \mathrm{H}-3 \mathrm{~b}(+8.9 \mathrm{~Hz})$, and $\mathrm{H}-5 \mathrm{a}(-17.1 \mathrm{~Hz})$, but was smaller for the other protons. However, the chemical shift variations on each side of the ester were consistent with the $S$ stereochemistry as shown in Figure 4. Therefore, the absolute stereochemistry of the $\alpha$-hydroxy acid moiety in [ $\beta$-Me-Pro] destruxin E chlorohydrin (1) was defined as $2(R), 4(S)$-5-chloro-2,4dihydroxypentanoic acid. Our approach is herein used for the first time to assign the absolute stereochemistry of the 5-chloro-2,4-dihydroxypentanoic acid residue, which is also present in destruxin E chlorohydrin (2) [6], destruxin A4 chlorohydrin [5], and in destruxin E2 chlorohydrin [13]. 


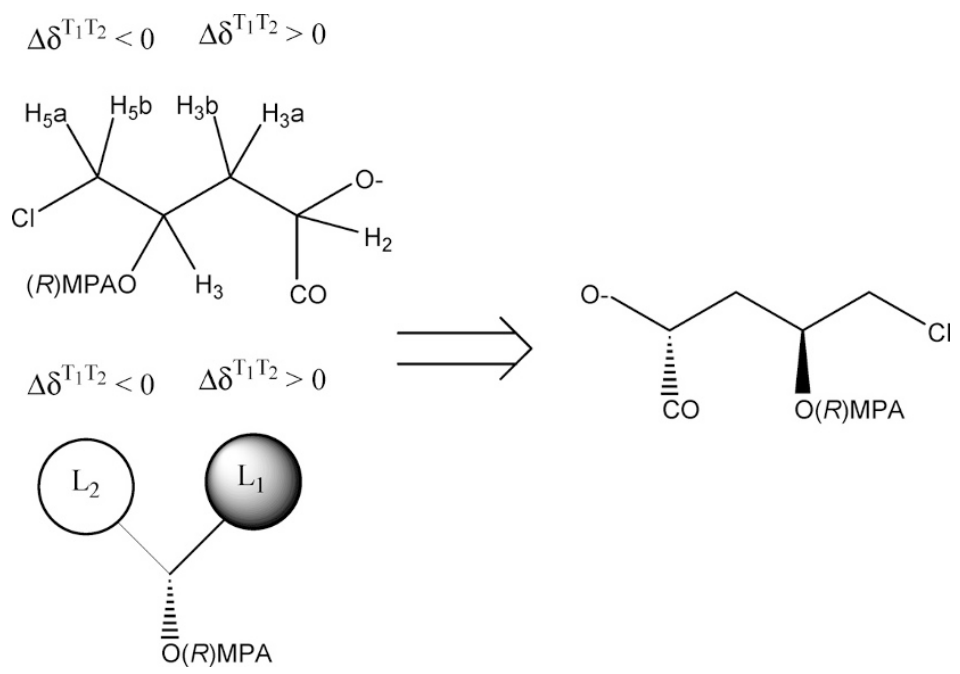

Fig. 4 Single derivative MPA ester analysis [10].

Pseudodestruxin C (3) was isolated as an optically active white solid, $[\alpha]_{\mathrm{D}}^{25}-122.4$ ( $\left.c 0.0213, \mathrm{MeOH}\right)$. The molecular formula $\mathrm{C}_{36} \mathrm{H}_{56} \mathrm{~N}_{5} \mathrm{O}_{7}$ was assigned by the HRFABMS analysis of the $[\mathrm{M}+\mathrm{H}]^{+}$peak at $m / z 670$ (meas. 670.4149; calc. 670.4179) and was consistent with the NMR data. The NMR data showed that pseudodestruxin C (3) contained two $N$-methyl groups (at $\delta 2.95$ and 3.08) and a $\beta$-Ala residue consistent with other members of the destruxin class of cyclodepsipeptides. The ${ }^{1} \mathrm{H}$ NMR clearly indicated the presence of a monosubstituted aromatic ring belonging to a phenylalanine residue $(\delta 7.30 \mathrm{~m} ; 7.27 \mathrm{~m} ; 7.24 \mathrm{~m})$. Additionally, analysis of the ${ }^{1} \mathrm{H}-{ }^{1} \mathrm{H}$ COSY and $80 \mathrm{~ms}$ TOCSY spectrum showed spin systems consistent with two $N$-Me-Val residues and a $\beta$-Me-Pro residue. The $\mathrm{H} \alpha$ of the hydroxy acid residue could easily be identified in the gHSQC spectrum due to the downfield shift of the ${ }^{13} \mathrm{C}$ resonance, typically assigned to $\mathrm{C} \alpha$ (at $\delta 74.6$ ). The ${ }^{1} \mathrm{H}-{ }^{1} \mathrm{H}$ couplings observed in both COSY and TOCSY spectra showed a spin system related to that of leucine, thereby elucidating the 2-hydroxy-4-methylpentanoic acid residue. Once the individual amino acid spin systems were assigned, the sequence could be assembled using HMBC data and ROESY correlations in a manner similar to that described for [ $\beta$-Me-Pro] destruxin $\mathrm{E}$ chlorohydrin (1), indicating the planar structure 3 for pseudodestruxin $C$, which is the $\beta$-Me-Pro analog of $\left[\mathrm{Ph}^{3}, N\right.$-Me-Val $\left.{ }^{5}\right]$ destruxin B (4) previously isolated from the same fungal strain Beauveria felina [14]. The absolute stereochemistry of the $N$-Me-Val and Phe residue has been established as $S$ by derivatization with Marfey's reagent followed by HPLC analysis. No attempt has been made to establish the absolute stereochemistry of the 2-hydroxy-4-methylpentanoic acid residue. The relative stereochemistry of the $\beta$-Me-Pro residue is proposed as $\mathrm{C} \alpha\left(S^{*}\right), \mathrm{C} \beta\left(S^{*}\right)$, the same of $[\beta$-MePro] destruxin E chlorohydrin (1), since the coupling constant for the $\mathrm{H} \alpha-\mathrm{H} \beta$ in the $\beta$-Me-Pro residue is practically the same for both compounds $1(J=2.54 \mathrm{~Hz})$ and $3(J=2.4 \mathrm{~Hz})$, and closely related to the same coupling observed in roseotoxin B [15]. We have named compound 3 pseudodestruxin $\mathrm{C}$ in agreement with Gloer's naming system for pseudodestruxins A and B [16]. In addition to the new compounds, we have isolated the known destruxins destruxin E chlorohydrin (2) [6] $\left[\mathrm{Ph}^{3}, N\right.$-Me-Val $\left.{ }^{5}\right]$ destruxin B (4) [14], roseotoxin B (5) $[15,17]$ and roseocardin (6) [18]. The structures of the known cyclodepsipeptides have been established by analysis of MS and NMR data and comparison with literature data. Interestingly, a nondestruxin peptide, isariin B (7), was also obtained from our marine-derived strain of $B$. felina. Initial inspection of the NMR data suggested that this peptide contained a methylene similar to that of a $\beta$-Ala. However, a detailed analysis showed that this methylene was a glycine and indicated the peptide was not a destruxinlike cyclodepsipeptide. Accurate mass measurements gave an $[\mathrm{M}+\mathrm{H}]^{+}$at $\mathrm{m} / \mathrm{z} 596.4025$ indicating the molecular formula $\mathrm{C}_{30} \mathrm{H}_{54} \mathrm{~N}_{5} \mathrm{O}_{7}$ for the quasi-molecular ion $[\mathrm{M}+\mathrm{H}]^{+}$ (calcd 596.4023, $\Delta 0.3 \mathrm{ppm}$ ). On the basis of the molecular formula, the compound was the known fungal metabolite isariin B (see Figure 5) [19, 20]. In order to confirm the structure without relying on extensive analysis of the NMR data, MS studies were performed on the $[\mathrm{M}+\mathrm{Na}]^{+}$ ion using a quadrupole orthogonal acceleration time of flight tandem mass spectrometer (Q-Tof) with +ESI. After fragmentation, the spectrum was calibrated using the residual parent $[\mathrm{M}+\mathrm{Na}]^{+}$ion to obtain accurate mass measurements on the fragment ions (see Figure 6). 
A molecular formula could easily be assigned to the fragments, but the sequence required knowledge of the fragmentation route. Therefore, in source CID fragmentation of the $[\mathrm{M}+\mathrm{Na}]^{+}$ion was performed and resulted in a spectrum that was similar to the MS/MS spectrum. Each of the resulting fragment ions was filtered by the quadrupole, fragmented in the collision cell, and analyzed by the TOF mass analyzer. From these analyses, $m / z 335$ and $m / z 236$ were identified as daughter ions of $\mathrm{m} / \mathrm{z} 448$, with $\mathrm{m} / \mathrm{z} 236$ being the only daughter ion observed upon fragmentation of $\mathrm{m} / \mathrm{z} 335$. Additionally, $\mathrm{m} / \mathrm{z} 289$ was a daughter ion of $\mathrm{m} / \mathrm{z}$ 402. These results confirmed not only the sequence of the amino acids, but also the molecular formula for each

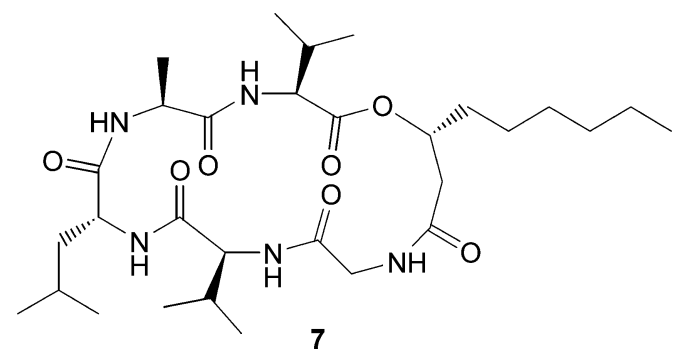

Fig. 5 Structure of isariin B (7). fragment ion. This methodology allows pseudo $\mathrm{MS}^{3}$ experiments while maintaining mass accuracy and should be widely applicable to the analysis of a variety of natural products, enabling the dereplication of peptide type natural products without the need for NMR analysis to confirm the amino acid sequence. The method can be summarized as it follows. In the first step, a lock mass is used to obtain accurate mass on the molecular ion. Once a molecular formula is confirmed, the MS/MS spectra can be mass corrected using the residual signal from the parent ion to achieve accurate mass on the fragments. Then, in source CID can be applied to allow mass filtering for MS/MS studies to track daughter ions, thereby allowing $\mathrm{MS}^{3}$ and efficient compound dereplication.

In conclusion, the present investigation reports the isolation of two new destruxin derivatives, $[\beta$-Me-Pro] destruxin E chlorohydrin (1) and pseudodestruxin C (3). Furthermore, the absolute stereochemistry of the 5-chloro2,4 -dihydroxypentanoic acid in [ $\beta$-Me-Pro] destruxin $\mathrm{E}$ chlorohydrin (1) has been assigned for the first time using a combination of the $J$-based configuration method $[10,11]$ in conjunction with the variable temperature NMR analysis of the corresponding $R$-MPA ester derivative. Finally, an $\mathrm{MS}^{3}$ method using in source CID to allow mass filtering for

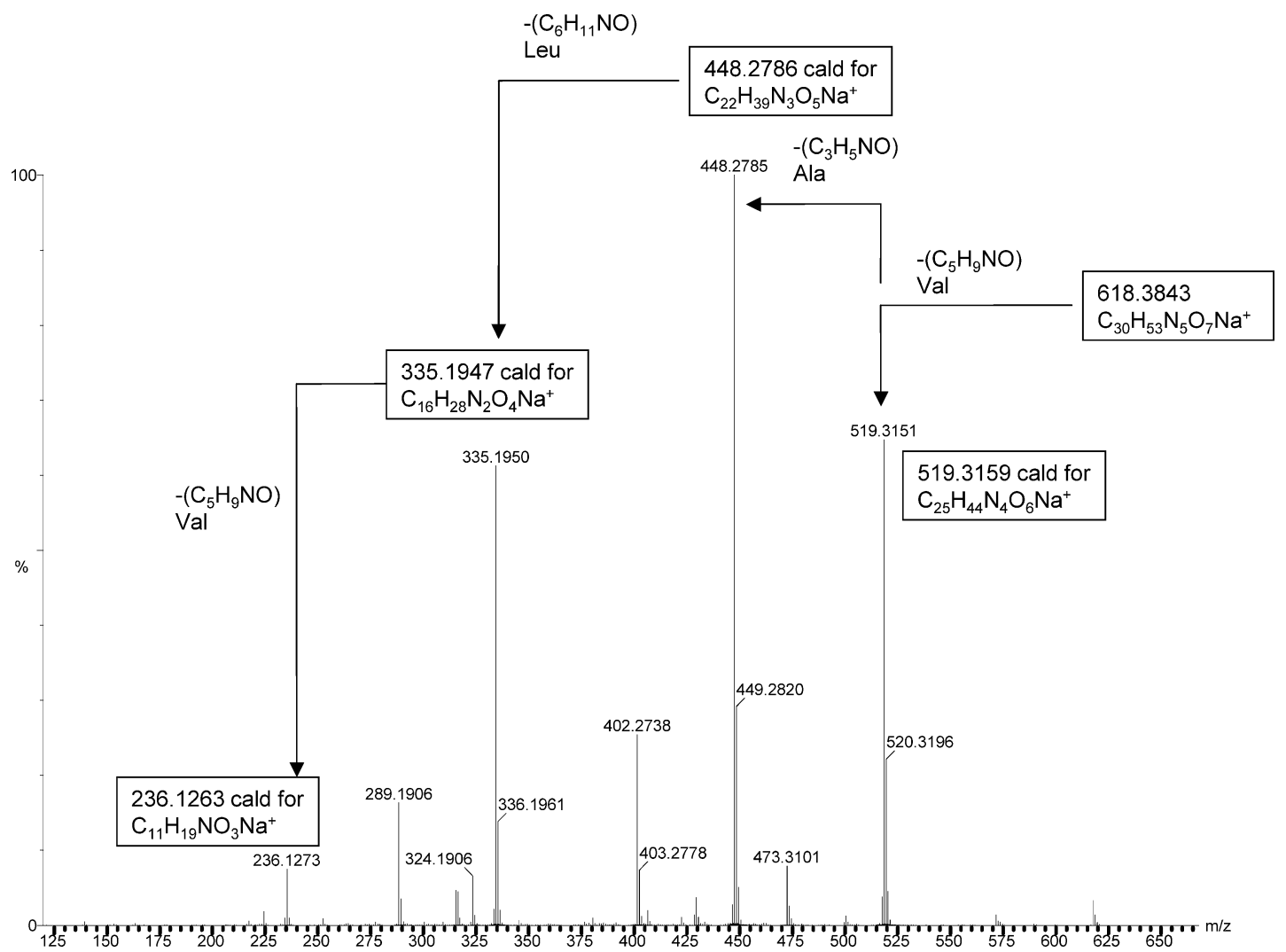

Fig. 6 MS sequencing of isariin B (7). 
additional MS/MS analysis to track daughter ions was developed for the rapid dereplication of natural products. Finally, the major compounds isolated from the marinederived B. felina, pseudodestruxin $\mathrm{C}(\mathbf{3}),\left[\mathrm{Phe}^{3}, N-\mathrm{Me}-\mathrm{Val}^{5}\right]$ destruxin B (4) and rosetoxin B (5), have been tested against M. tuberculosis $\mathrm{H} 37 \mathrm{Rv}$ and in cytotoxicity bioassays against SF 295 (human CNS), MDA-MB435 (human breast), HCT8 (colon) and HL60 (leukemia) cancer cell lines. Only roseotoxin B displayed moderate cytotoxicity at $1.09,1.30,0.90$ and $0.14 \mu \mathrm{g} / \mathrm{ml}$ against each of the cell lines, respectively.

Acknowledgments The authors thank Dr. Álvaro Esteves Migotto, Director of the Centro de Biologia Marinha of the Universidade de São Paulo, for providing facilities for marine sample collection, Prof. Gil V. J. Silva and Virginia H. B. Glass (Departamento de Química, Faculdade de Filosofia, Ciências e Letras de Ribeirão Preto, Universidade de São Paulo) for obtaining the NMR spectra on the Bruker DRX500 NMR equipment, and Professor Brent R. Copp (Department of Chemistry, University of Auckland, New Zealand) for obtaining the MS data for compound 3. Financial support was provided by the FAPESP grant $03 / 08899-0$ and the CNPq grant $470481 / 04-8$ to RGSB, a FAPESP scholarship 03/06471-3 to SPL, a CAPES scholarship to AMV-M, a USP-PROCONTES contract to MHRS and NIH grant CA36622 to CMI. The following NIH and NSF grants funded the Varian NMR instrumentation, RR06262, RR13030, and DBI-0002806. The authors dedicate this work to the memory of Professor Kenneth Lloyd Rinehart, for his outstanding achievements in the discovery of biologically active natural products.

\section{References}

1. Bugni TS, Ireland CM. Marine-derived fungi: a chemically and biologically diverse group of microorganisms. Nat Prod Rep 21: 143-163 (2004)

2. Kelecom A. Secondary metabolites from marine microorganisms. An Acad Bras Ciências 74: 151-170 (2002)

3. Hernandez ILC, Godinho MJL, Magalhães A, Schefer AB, Ferreira AG, Berlinck RGS. $N$-Acetyl- $\gamma$-hydroxyvaline lactone, an unusual amino acid derivative from a marine streptomycete. J Nat Prod 63: 664-665 (2000)

4. Hernandez ILC, Macedo ML, Berlinck RGS, Ferreira AG, Godinho MJl. Dipeptide metabolites from the marine derived bacterium Streptomyces acrymicini. J Braz Chem Soc 15: 441-444 (2004)

5. Cai P, Smith D, Katz B, Pearce C, Venables D, Houck D. Destruxin-A4 chlorohydrin, a novel destruxin from fungus OS-F68576: isolation, structure determination, and biological activity as an inducer of erythropoietin. J Nat Prod 61: 290-293 (1998)
6. Gupta S, Roberts DW, Renwick JAA. Insecticidal cyclodepsipeptides from Metarrhizium anisopliae. J Chem Soc Perkin Trans I 2347-2357 (1989)

7. Bhushan R, Bruckner H. Marfey's reagent for chiral amino acid analysis: a review. Amino Acids 27: 231-247 (2004)

8. Matsumori N, Kaneno D, Murata M, Nakamura H, Tachibana K. Stereochemical determination of acyclic structures based on carbon-proton spin-coupling constants. A method of configuration analysis for natural products. J Org Chem 64: 866-876 (1999)

9. Murata M, Matsuoka S, Matsumori N, Paul GK, Tachibana K. Absolute configuration of amphidinol 3, the first complete structure determination from amphidionol homologues: Application of a new configuration analysis based on carbon-hydrogen spin-coupling constants. J Am Chem Soc 121: 870-871 (1999)

10. Latypov SK, Seco JM, Quiñoá E, Riguera R. Are both the $(R)$ - and the $(S)$-MPA esters really needed for the assignment of the absolute configuration of secondary alcohols by NMR? The use of a single derivative. J Am Chem Soc 120: 877-882 (1998)

11. Uhrin D, Batta G, Hruby VJ, Barlow PN, Kover KE. Sensitivity- and gradient-enhanced hetero $(\omega 1)$ half-filtered TOCSY experiment for measuring long-range heteronuclear coupling constants. J Mag Res 130: 155-161 (1998)

12. Williamson RT, Boulanger A, Vulpanovici A, Roberts MA, Gerwick WH. Structure and absolute stereochemistry of phomidolide, a new toxic metabolite from the marine cyanobacterium Phormidium sp. J Org Chem 67: 7927-7936 (2002)

13. Yeh SF, Pan W, Ong GT, Chiou AJ, Chuang CC, Chiou SH, $\mathrm{Wu} \mathrm{SH}$. Study of structure-activity correlation in destruxins, a class of cyclodepsipeptides possessing suppressive effect on the generation of hepatitis B virus surface antigen in human hepatoma cells. Biochem Biophys Res Commun 229: 65-72 (1996)

14. Kim HS, Jung MH, Ahn S, Lee CW, Kim SN, Ok JH. Structure elucidation of a new cyclic hexadepsipeptide from Beauveria felina. J Antibiot 55: 598-601 (2002)

15. Springer JP, Cole RJ, Dorner JW, Cox RH, Richard JL, Barnes CL, Van der Helm D. Structure and conformation of roseotoxin B. J Am Chem Soc 106: 2388-2392 (1984)

16. Che Y, Swenson DC, Gloer JB, Koster B, Malloch D. Pseudodestruxins A and B: new cyclic depsipeptides from the Coprophilous fungus Nigrosabulum globosum. J Nat Prod 64: 555-558 (2001)

17. Engstrom GW, DeLance JV, Richard JL, Baetz AL. Purification and characterization of roseotoxin B, a toxic cyclodepsipeptide from Trichothecium roseum. J Agric Food Chem 23: 244-253 (1975)

18. Tsunoo A, Kamijo M, Taketomo N, Sato Y, Ajisaka K. Roseocardin, a novel cardiotonic cyclodepsipeptide from Trichothecium roseum TT103. J Antibiot 50: 1007-1013 (1997)

19. Baute R, Deffieux G, Merlet D, Baute MA, Neveu A. New 
insecticidal cyclodepsipeptides from the fungus Isaria felina. I. Production, isolation and insecticidal properties of isariins B, C and D. J Antibiot 34: 1261-1265 (1981)

20. Deffieux G, Merlet D, Baute R, Bourgeois G, Baute MS, Neveu A. New insecticidal cyclodepsipeptides from the fungus Isaria felina. II. Structure elucidation of isariins B, C and D. J Antibiot 34: 1266-1270 (1981)

21. Raeder J, Broda P. Rapid preparation of DNA from filamentous fungi. Lett Appl Microbiol 1: 17-20 (1985)

22. Thompson JD, Higgins DG, Gibson TJ, Clustal W. Improving the sensitivity of progressive multiple alignment through sequence weighting, positions-specific gap penalties and weight matrix choice. Nucl Acids Res 22: 4673-4680 (1994)
23. Kumar S, Tamura K, Jakobsen IB, Nei M. MEGA2: Molecular Evolutionary Genetics Analysis software, Arizona State University, Tempe, Arizona, USA. Bioinform 17: 1244-1245 (2001)

24. Kimura M. A simple method for estimating evolutionary rate of base substitutions through comparative studies of nucleotide sequences. J Mol Evol 16: 111-120 (1980)

25. Abad J-L, Fabrias G, Camps F. Synthesis of dideuterated and enantiomers of monodeuterated tridecanoic acids at C-9 and C-10 positions. J Org Chem 65: 8582-8588 (2000)

26. Ward DE, Rhee CK. A simple method for the microscale preparation of Mosher's acid chloride. Tetrahedron Lett 32: 7165-7166 (1991) 